же нормализация вегетативных функций у женщин в период пре- и менопаузы. Препарат Цефавора возможно рекомендовать для периодических курсов в монотерапии или в комплексном лечении.

Ключевые слова: цефалгический синдром, вегетативная дистония, пре- и менопауза у женщин, Цефавора.

\title{
Treatment of neurological disorders of women in the period of pre- and menopausal using complex homeopathic drugse
}

Prof. T.A. Litovchenko, PHD O.L. Tondiy, PHD O.P. Zavalnaya

Kharkov Medical Academy of Postgraduate Education

We evaluated the efficacy of a homeopathic drug Cefavora (Cefak, Germany) in the correction of headaches with dystonia in women during pre- and menopause. The studied group included 50 women aged 37 to 55 years who were cephalalgia various origins and manifestations of vegetative dystonia. All patients underwent clinical, neurological and psychological examination. The proposed formulation combines vasoactive, veno-tonic, neuroprotective, cardiotonic effect, improves blood rheology and microcirculation. As a result, the treatment of positive dynamics in the clinical picture, as a decrease in intensity cephalgic syndrome, as well as normalization of autonomic function in women during pre- and menopause. Cefavora may be recommended for periodic courses in monotherapy or combined treatment.

Key words: cephalgic syndrome, vegetative dystonia, pre- and menopausal women Cefavora.

Контактна інформація: Літовченко Тетяна Анатоліївна зав. кафедрою невропатології та дитячої неврології ХМАПО, доктор медичних наук, професор. м. Харків, вул. Балакірєва, 5, м. т. 067-736-66-09, 067-298-92-33, e-mail: neurosurgery@med.edu.ua.

Стаття надійшла до редакції 16.10.2014 p.
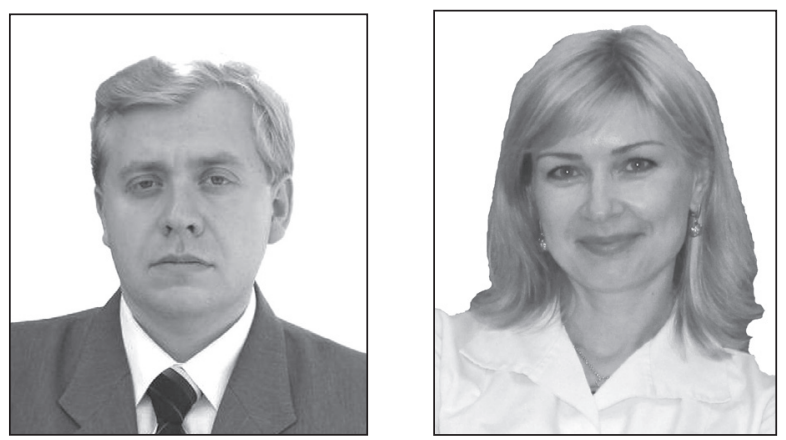

Проф. А.А. Опарин, доц. Н.В. Лаврова

Харьковская медицинская академия последипломного образования

Кафедра терапии, ревматологии

и клинической фармакологии

\section{Гастроэзофагеацьная рефмюксная болезнь. Проблематика. Аиагностика. Аечение}

$\mathrm{B}$ последние годы среди заболеваний не только пищеварительного тракта, но и клиники внутренних болезней в целом, особое место стала занимать гастроэзофагеальная рефлюксная болезнь (ГЭРБ) [6, $7,13,38]$.

Гастроэзофагеальная рефлюксная болезнь (К 21) - это хроническое рецидивирующее заболевание, обусловленное спонтанным, регулярно повторяющимся забросом в пищевод желудочного и/или дуоденального содержимого, приводящим к повреждению дистального отдела пищевода и появлению характерных симптомов (изжога, ретростернальные боли, дисфагия).

Примечательно, что еще 40-50 лет назад о таком заболевании никто не говорил вообе, и буквально за считанные годы оно стало занимать одно из ведущих мест по распространению, поражению лиц молодого и среднего возраста, количеству осложнений, что обуславливает не только медицинское, но и социальное значение этой проблемы $[13,27,35]$.

Особую проблематику данного заболевания обуславливают и следующие факторы: 
- Отсутствие четких критериев диагностики и качества проводимой терапии;

- Длительное, часто пожизненное лечение;

- Снижение качества жизни, сопоставимое как при ГБ и ИБС.

Причем распространение ГЭРБа отмечается в первую очередь в экономически развитых странах, в то время, как в странах «третьего мира» данное заболевание встречается редко [10, 19, 33].

Какие же факторы, привели к формировнию данного заболевания, прогрессированию его распространения, особенно среди лиц трудоспособного возраста и в экономически развитых странах.

Среди этих факторов мы можем выделить следующие.

\section{Этиологические и предрасполагающие факторы}

Несмотря на кажущуюся простоту, хотелось бы остановиться на факторах, предрасполагающих к формированию ГЭРБ, поскольку исключение этих факторов является и одним из необходимых направлений успешной, как профилактики, так и лечения данного заболевания.

- Стресс. Он приводит к выбросу адреналина и других шоковых ядов, усилению работы обкладочных клеток, вырабатывающих соляную кислоту, спазмам сосудов, сбоям в регуляции центральной и вегетативной нервной системы, нарушению моторики и перистальтики ЖКТ.

- Гиподинамия. Она приводит к ослаблению моторики ЖКТ, застою пищи в желудке и кишечнике, появлению отрыжки и изжоги, ухудшению регионарного кровотока, что создает условия для нарушения деятельности пищеводного сфинктера и формирования ГЭРБ.

- Курение и алкоголь. Эти вредные привычки ведут к резкому повышению выработки соляной кислоты, ухудшению регионарного кровотока, поражению нервно-мышечного аппарата сфинктеров, нарушению работы вегетативной нервной системы.

- Употребление кофе и чая. Данные продукты питания, с одной стороны, стимулируют выработку соляной кислоты, вследствие чего провоцируется поражение слизистой желудка, а с другой, - особенно натощак, способствуют формированию изжоги и обратной перистальтики.

- Употребление морепродуктов и свинины. Ставшие сегодня столь популярными морепродукты представляют для здоровья человека не малую опасность. Дело в том, что раки и крабы питаются падалью, и в их мясе содержится значительное количество так называемого «трупного яда», который, кроме всего прочего, приводит к расслаблению нижнего пищеводного сфинктера. Мидии являются санитарами моря, появляясь в большом количестве, особенно после шторма, для очищения морских бассейнов, собирают на себя различные токсины, подобно губке. Эти многочисленнейшие токсины при употреблении мидий попадают в организм человека, приводя, в частности, к росту общего аллергического фона и нарушению деятельности пищеводного сфинктера.
Употребление свиного мяса также неблагоприятно для здоровья человека. Дело в том, что при употреблении белка человеческий организм должен получать его не только в достаточном количественном, но и качественном отношении. В то время как свиное мясо содержит избыток аминокислот, в которых человеческий организм нуждается меньше и недостаток тех, которые организму нужны в большем количестве. Свиной жир относится к категории тугоплавких жиров, которые ферментативная система организма человека не может своевременно и качественно расщепить. В результате пища задерживается в желудке, вызывая часто обратную перистальтику. Отсюда после употребления свинины у больных возникает чувство тяжести в желудке, отрыжка, изжога , приводя в дальнейшем к развитию хронических панкреатитов, гастритов, холециститов и ГЭРБ. Примечательно, что в исламских странах или регионах с компактным проживанием мусульман, данные виды патологий практически не встречаются. Так же вследствие того, что свиное мясо содержит огромное количество токсинов (о том, чем питается свинья много писать не нужно), которые практически не уничтожаются при кулинарной обработке, оно способствует, кроме всего прочего, в частности, нарушению регуляции ЖКТ и его сфинктеров. Следует отметить, также, огромный риск развития трихинеллеза у любителей свинины.

Также, говоря о роли продуктов питания, являющихся предрасполагающими факторами, принимающими участие в формировании ГЭРБ и актуальными для нашей местности, стоит остановиться и на мясе кролика, которое длительное время считалось диетическим. Действительно, там содержится небольшое количество жиров. Однако, вследствие того, что нервная система данного животного весьма лабильна, у него практически постоянно выбрасывается в кровь большое количество адреналина, норадреналина и других шоковых ядов, продукты распада которых откладываются в его мясе. При употреблении последнего человек получает и эти продукты распада, которые вызывают, в частности, и сбой в работе ЖКТ.

- Употребление копченых и полукопченых продуктов. Данные продукты питания крайне плохо расщепляются ферментативной системой организма человека, вследствие чего происходит застой пищи в желудке. Так же вредные вещества, образующиеся в процессе копчения, снижают моторику ЖКТ и расслабляют его сфинктеры.

- Нерегулярное питание. Оно приводит, как правило, к перееданию во второй половине дня, в результате чего в желудок поступает большой объем пищи, с которой он эффективно справиться не может, вследствие чего со временем формируется гастростаз, способствующий формированию обратной перистальтики, отрыжки и изжоги. Также, длительные промежутки между приемами пищи приводят к раздражающему действию соляной кислоты на слизистую оболочку желудка, что способствует развитию воспалительных заболеваний слизистой ЖКТ и его функциональным нарушениям. 
- Избыточная масса тела. Приводит к снижению перистальтики ЖКТ, повышению внутрибрюшного давления.

Как видим, вышеуказанные факторы действительно имеют распространение, в первую очередь (или вообще только), в экономически развитых странах с высоким темпом жизни, урбанизацией и развитием пищевой промышленности. Эти этиологические предрасполагающие факторы приводят к снижению функции антирефлюксного барьера, нарушению клиренса пищевода и деятельности нижнего пищеводного сфинктера, нарушению перистальтики желудка, что осуществляется следующими механизмами.

- Патофизиологические механизмы формирования заболевания

1. Снижение функции антирефлюксного барьера, которое может происходить тремя путями:

a) Первичное снижение давления в нижнем пищеводном сфинктере;

б) Увеличение числа эпизодов его спонтанного расслабления;

в) Полная или частичная его деструктуризация, например, при грыже пищеводного отверстия диафрагмы.

2. Снижение клиренса пищевода:

а) Химического - вследствие уменьшения нейтрализующего действия слюны и бикарбонатов пищеводной слизи.

б) Объемного - из-за угнетения вторичной перистальтики и снижения тонуса стенки грудного отдела пищевода.

3. Повреждающие свойства рефлюктата (соляная кислота, пепсин, желчные кислоты).

4. Неспособность слизистой оболочки пищевода противостоять повреждающему действию.

5. Нарушение опорожнения желудка.

6. Повышение внутрибрюшного давления.

Таким образом, ГЭРБ является кислотозависимым заболеванием, развивающимся на фоне первичного нарушения двигательной функции верхних отделов пищеварительного тракта [3, 12, 16, 23, 24, 27, 36].

\section{- Клиника}

В клинической картине ГЭРБ принято выделять пищеводные и внепищеводные симптомы.

- Пищеводные симптомы:

- Изжога (83\% больных);

- Отрыжка (52\% больных);

- Дисфагия (19\% больных).

- Внепищеводные симптомы:

Ротоглоточные симптомы:

- воспаление носоглотки;

- повреждения эмали зубов;

- фарингит, ларингит.

Респираторные симптомы:

- хронический бронхит;

- аспирационная пневмония;

- приступы пароксизмального кашля;

- бронхиальная астма.

Кардиальные симптомы:

- боль за грудиной;

- рефлекторная стенокардия.
Анемический симптом.

Следует иметь в виду и это хочется подчеркнуть особо, что в клинике ГЭРБ внепищеводные симптомы часто выходят на передний план, заслоняя саму ГЭРБ, что ведет к неверной постановке диагноза, малоэффективному лечению и прогрессированию основного заболевания - ГЭРБ $[1,4,8,9,28,33]$.

Так, только примерно более одной трети всех случаев бронхиальной астмы обусловлены ГЭРБ [9].

Так же установлена четкая корреляционная зависимость между частотой и выраженностью изжоги и развитием аденокарциномы пищевода $[6,13]$.

\section{- Осложнения}

- Стриктуры пищевода.

- Кровотечение из язв пищевода.

- Пищевод Барретта (некоторые авторы предлагают рассматривать его, как одну из форм ГЭРБ) - это замещение многослойного плоского эпителия в нижней трети пищевода, вследствие постоянной агрессии кислого содержимого кишечным цилиндрическим эпителием, который при ФГДС имеет бархатистый вельветообразный вид. Пищевод Барретта является предраковым состоянием.

- Аденокарцинома пищевода.

- Объективный статус и лабораторная диагностика - без особенностей.

\section{- Инструментальная диагностика}

- ФГДС - определение признаков эзофагита при эрозивной форме ГЭРБ. Реже отмечается зияние нижнего пищеводного сфинктера и пролабирование слизистой желудка в пищевод.

- Гастрохромоэндоскопия. Данный метод исследования применяют особенно в тех случаях, когда необходимо подтвердить диагноз пищевода Барретта.

Данная методика состоит из двух основных этапов.

1. С помощью специального спрея - катетора на слизистую пищевода наносится краситель, который имеет тропность к клеткам кишечного эпителия;

2. С помощью воды краситель смывается, оставаясь только на тех участках слизистой пищевода, которые подверглись структурной перестройке.

Современные фиброгастроскопы позволяют проводить исследование с увеличением, что позволяет практически на месте поставить диагноз пищевода Барретта [6, 18, 25].

- pH-метрия - у большинства больных гиперацидность в теле желудка.

- Рентген - заброс контрастной массы в пищевод.

- 24-часовая билиметрия. Она представляет собой суточное измерение концентрации билирубина в пищеводе, осуществляемое с помощью фиброоптической спектрофотометрической системы. При этом она является единственным достоверным методом регистрации патологического щелочного рефлюкса $[6,13,25]$.

- Классификация

По МКБ-10

- ГЭРБ с эзофагитом (К21.0);

- ГЭРБ без эзофагита (К21.9). 


\begin{tabular}{|c|c|}
\hline \multicolumn{2}{|r|}{$\begin{array}{c}\text { Лос-Анджелесская классификация } \\
\text { рефлюкс-эзофагита }\end{array}$} \\
\hline $\begin{array}{c}\text { Степень } \\
\text { тяжести } \\
\text { РЭ }\end{array}$ & Характеристика изменений \\
\hline A & $\begin{array}{l}\text { Одно или несколько повреждений слизистой } \\
\text { оболочки пищевода, каждое из которых длиной } \\
\text { не более } 5 \text { мм, ограниченное одной складкой } \\
\text { слизистой оболочки }\end{array}$ \\
\hline B & $\begin{array}{l}\text { Одно или несколько повреждений слизистой } \\
\text { оболочки пищевода длиной более } 5 \text { мм, ограни- } \\
\text { ченное складками слизистой оболочки, причем } \\
\text { повреждения не распространяются между дву- } \\
\text { мя складками }\end{array}$ \\
\hline C & $\begin{array}{l}\text { Одно или несколько повреждений слизистой } \\
\text { оболочки пищевода длиной более } 5 \text { мм, ограни- } \\
\text { ченное складками слизистой оболочки, причем } \\
\text { повреждения распространяются между двумя } \\
\text { складками, но занимают менее } 75 \% \text { окружности } \\
\text { пищевода }\end{array}$ \\
\hline D & $\begin{array}{l}\text { Повреждения слизистой оболочки пищевода, } \\
\text { охватывающие } 75 \% \text { и более по его окружности }\end{array}$ \\
\hline
\end{tabular}

Таблица 1.2

Классификация рефлюкс-эзофагита по Savary-Miller в модификации Carrison et.al.

\begin{tabular}{|c|c|}
\hline $\begin{array}{l}\text { Степень } \\
\text { тяжести }\end{array}$ & Характеристика изменений \\
\hline 0 & Признаки рефлюкс-эзофагита отсутствуют \\
\hline I & $\begin{array}{l}\text { Одно (или более) отдельное линейное повреж- } \\
\text { дение (эрозия) слизистой оболочки с эрите- } \\
\text { мой, часто покрытое экссудатом, занимающие } \\
\text { менее } 10 \% \text { окружности дистального отдела } \\
\text { пищевода }\end{array}$ \\
\hline II & $\begin{array}{l}\text { Сливные эрозивные повреждения слизистой } \\
\text { оболочки, занимающие 10-50\% окружности } \\
\text { дистального отдела пищевода }\end{array}$ \\
\hline III & $\begin{array}{l}\text { Множественные эрозивные повреждения, за- } \\
\text { нимающие практически всю окружность дис- } \\
\text { тального отдела пищевода }\end{array}$ \\
\hline IV & $\begin{array}{l}\text { Осложненные формы рефлюкс-эзофагита: } \\
\text { язва, стриктура, пищевод Барретта }\end{array}$ \\
\hline
\end{tabular}

\section{Амстердамская классификация}

- Неэрозивная форма (НЭРБ) - наиболее частая (60\% всех случаев ГЭРБ), благоприятно текущая форма, к которой относят ГЭРБ без признаков эзофагита и катаральный РЭ;

- Эрозивно-язвенная форма (34\%) и ее осложнения: язва и стриктура пищевода;

- Пищевод Барретта (6\%).

\section{Классификация по степени тяжести}

I (легкая) - симптомы появляются не чаще одного раза в месяц, длительность заболевания не превышает 6 месяцев;

II (умеренная) - симптомы возникают чаще одного раза в месяц, длительность заболевания составляет от 0,5 до 2 лет;

III (выраженная) - симптомы беспокоят чаще одного раза в неделю, но не ежедневно, мешают ве- сти нормальный образ жизни, длительность заболевания от 2 до 5 лет;

IV (тяжелая) - симптомы наблюдаются ежедневно, резко выражены, длительность заболевания более 5 лет

- Клинико-статистическая классификация болезни: Макет диагноза: Гастроэзофагеальная рефбюксная болезнь с эзоббагитом (T), (Q), осложненная (O)

T-степень тяжести эзофагита при ГЭРБ

Т1 - 1 степень тяжести, (слабо выраженная очаговая или дифбузная эритема и рыхлость слизистой на уровне ЖПС, легкая сглаженность, исчезновение блеска слизистой дистального отдела пищевода);

Т2 - 2 степень тяжести, (наличие одной или более поверхностных эрозий с или без налета, чащзе линейной формы, располагающиеся на верхушках складок слизистой пищевода. Занимают менее $10 \%$ поверхности дистальной части пищевода);

Т3 - 3 степень тяжести, (сливающиеся эрозии, покрытые налетом или отторгающимися некротическими массами. Объем поражения слизистой дистального отдела пищевода менее 50\%);

Т4 - 4 степень тяжести, (сливающиеся эрозии или эрозивно-некротические повреждения, занимающие всю зону пищевода выше ЖПС);

Т5 - 5 степень тяжести, (глубокие избязвления и эрозии в разных отделах пищевода, стриктурь, биброз стенок, короткий пищеевод).

$Q$ - особенности клинического проявления

Q1 - латентное течение;

Q2 - болевая форма;

Q3 - псевдокоронарная борма;

Q4 - геморрагически-анемическая форма;

Q5 - диспептическая форма;

Q6 - бронхо-пищеводная форма.

$\mathrm{O}$ - осложнения

О1 - острым кровотечением (Т степени);

(T1) - легкой степени;

(Т2) - средней степени;

(Т3) - тяжелой степени;

О2 - рецидивируюшим кровотечением;

О3 - постгеморрагической анемией.

Как видим, наибольшую трудность в постановке диагноза вызывает неэрозивная форма ГЭРБ, при которой не выявляется никаких изменений при проведении инструментальных и лабораторных методов исследования [5,6,25].

\section{- Пример формулировки диагноза}

МКБ-10 К21.9. Гастроэзофагеальная рефлюксная болезнь без эзофагита (рефлюкс-эзофагит 0 степени), стадия нестойкой ремиссии.

МКБ-10 К21.0. Гастроэзофагеальная рефлюксная болезнь: эрозивно-язвенный рефлюкс-эзофагит III степени тяжести.

МКБ-10 К21.0. Гастроэзофагеальная рефлюксная болезнь: рефлюкс-эзофагит IV степени тяжести, язва (5х6 мм) на задней стенке проксимального отдела пищевода, осложненная кровотечением легкой степени. 
- Перечень и объем медицинских услуг обязательного ассортимента согласно потоколов МO3 Украины

Диагностика:

- ЭКГ - однократно;

- Тест с ИПП - однократно;

- Перечень и объем медицинских услуг дополнительного ассортимента согласно протоколам МОЗ Украины

- Эндоскопия показана:

1. При неэффективности эпирического лечения;

2. При наличии тревожных симптомов;

3. Больным старше 40 лет;

4. При длительном анамнезе болезни (5 лет и более);

5. В случае спорного диагноза или при наличии атипичных симптомов;

6. В комплексе предоперационной подготовки.

- Хромоэндоскопия с метиленовым синим:

Показана пациентам с анамнезом заболевания 5 лет и более для выявления участков кишечной метаплазии (пищевода Барретта), с дальнейшей биопсией этих участков.

\section{- Биопсия:}

1. Показана, если при верхней эндоскопии возникло подозрение на кишечную метаплазию, независимо от длительности анамнеза болезни;

2. Должна выполнятся у пациентов с язвенным поражением пищевода и/или его стенозом, а также в случае подозрения нерефлюксной этиологии эзофагита;

3. Не показана пациентам с эрозивным эзофагитом при отсутствии показаний, которые перечислены в пунктах 1 и 2.

- 24-часовой внутрипищеводный $\mathrm{pH}$-мониторинг:

Основной метод подтверждения ГЭРБ, что дает возможность доказать связь симптомов (как типичных, так и атипичных) с желудочно-пищеводным рефлюксом;

- Рентгенологическое обследование пищевода (при подозрении на диафрагмальную грыжу);

- $\mathrm{pH}$-мониторинг при помощи радиотелеметрической системы «Bravo» имеет ряд преимуществ перед традиционным зондовым методом;

- Tест на Helicobacter pylori (Hp) - однократно;

Выявление и эрадикация Нр-инфекции показаны в случае необходимости длительной терапии при помощи ИПП;

- Общий анализ крови и биохимические исследования - однократно.

При неэффективности лечения на протяжении 2 недель необходимо проводить ФГДС и рН-мониторинг. При подтверждении диагноза доза ИПП увеличивается - назначается прием их стандартной дозы два раза в сутки с интервалом в 12 часов, иногда дополнительно назначают прокинетики. В случаях ночного «прорыва» кислотности, подтвержденного данными pH-мониторинга, показано дополнительное к двойной дозе ИПП применение Н2-гистаминблокаторов в стандартной дозе. При наличии желчного рефлюк- са показано применение урсодезоксихолевой кислоты или цитопротекторов.

\section{Эндоскопическое и хирургическое лечение ГЭРБ и пищевода Барретта}

Хирургическое и эндоскопическое лечение ГЭРБ может быть рекомендовано пациенту в следующих случаях:

1. Необходимость длительной медикаментозной терапии;

2. Недостаточный эффект медикаментозного лечения;

3. Диафрагмальная грыжа, большой объем рефлюксата;

4. Осложненная ГЭРБ (кровотечение, стриктуры, ПБ, рак пищевода);

5. Повторные аспирационные пневмонии;

6. Личное желание пациента.

\section{- Лечение}

Общие рекомендации по режиму и диете. Основные правила, которые постоянно должен соблюдать больной, не зависимо от степени выраженности РЭ и стадии заболевания:

- после принятия пищи избегать наклонов вперед и не ложиться;

- спать с приподнятой верхней частью туловища (подъем головного конца кровати не менее чем на 15 см), что значительно уменьшает интенсивность рефлюкса;

- избегать тесной одежды и тугих поясов, снизить избыточную массу тела, полностью исключить поднятие тяжестей более 8-10 кг, выполнение работ, связанных с наклоном туловища вперед, физических упражнений, связанных с перенапряжением мышц брюшного пресса для снижения и профилактики повышения внутрибрюшного давления;

- избегать обильных приемов пищи, не есть на ночь и не употреблять слишком горячей еды;

- ограничить потребление продуктов, вызывающих снижение давления НПС и обладающих раздражающим действием;

- отказ от курения и употребления алкоголя;

- при возможности отказ от приема лекарств, вызывающих рефлюкс (антихолинергические, спазмолитики, седативные и транквилизаторы, ингибиторы кальциевых каналов, $\beta$-блокаторы, теофиллин, простагландины, нитраты, нестероидные противовоспалительные средства, хинидин и др.).

- Принимать пищу 4-6 раз в день небольшими порциями, с последним приемом пищи не менее чем за 3 часа до сна. Не употреблять кислые фруктовые соки, продукты, усиливающие газообразование и снижающие тонус нижнего пищеводного сфинктеpa (чеснок, лук, перец, кофе, шоколад) - в рационе рекомендуется повышенное употребление белковой пищи.

При этом стоит особо подчеркнуть, что соблюдение правильного образа жизни и диеты имеет при ГЭРБ принципиальное, а на ранних стадиях развития заболевания решающее значение $[6,13,21]$. 
Основные принципы фармакотерапии ГЭРБ

- снижение агрессии желудочного сока на слизистую пищевода;

- повышение антирефлюксной функции нижнего пищеводного сфинктера;

- усиление эзофагеального очищения;

- защита слизистой пищевода от повреждения $[2,23,24,30,38,43]$.

Эффект медикаментозной терапии ГЭРБ должен предусматривать:

- Быстрое и полное купирование основных симптомов заболевания, прежде всего изжоги;

- Улучшение эндоскопической картины;

- Высокую степень безопасности;

- Улучшение качества жизни;

- Оптимальное соответствие понятию «эффективность \стоимость» $[6,24,25]$.

- Лечение согласно протоколов МO3 Украины

Лечение ГЭРБ делится на 2 фазы:

- Первая фаза - начальное лечение ГЭРБ в стадии обострения, целью которого является заживление эрозивного эзофагита, полное купирование клинических проявлений;

- Вторая фаза - длительное лечение, целью которого является поддержание ремиссии.

Начальное лечение ГЭРБ. Минимальная длительность начального лечения при неэрозивной ГЭРБ 4 недели с дальнейшим переходом на дозу, которая поддерживает ремиссию еще, как минимум, 4 недели. При эрозивной ГЭРБ длительность начального лечения должна составлять от 4 до 12 недель, в зависимости от степени эзофагита с последующим длительным назначением одной из схем длительной терапии. Общепринятой стратегией лечения ГЭРБ является стратегия лечения антисекреторными препаратами Step-down: начальное назначение двойных или стандартных доз ИПП на протяжении 4-8 недель (в зависимости от тяжести ГЭРБ или НЭРБ) с дальнейшим переходом на длительное лечение по разным схемам. Альтернативными методами лечения являются эндоскопические и хирургические методы лечения.

Длительное лечение ГЭРБ может проводиться в 3 вариантах:

1. Длительный ежедневный прием ИПП в противорецидивных дозах;

2. Терапия «по требованию»: прием ИПП в полной дозе коротким 3-5-дневным курсом при возобновлении симптоматики;

3. Терапия «выходного дня»: прием ИПП в противорецидивной дозе два дня в неделю (например, суббота и воскресенье).

\section{- Ингибиторы протонной помпы}

В настоящее время данная группа препаратов является основной при лечении ГЭРБ.

Существуют, как отмечалось выше, три основные схемы-подхода к назначению ИПП при ГЭРБ. Как правило, при ГЭРБ ИПП назначаются в среднем в течении $4-5$ недель, по 20 мг утром и вечером [11, 12, 4, 32, 40].

PPI (proton pump inhibitor)-тест представляет собой курс пробного лечения с помощью какого-либо из препаратов группы ИПП в стандартной дозе. Стандартная длительность омепразолового теста 14 дней, чувствительность метода при этом составляет 68-80\%. Его положительная оценка рассматривается, как свидетельствующая в пользу ГЭРБ.

\section{- Прокинетики}

Применяются, как вспомогательное средство терапии.

Использование препаратов данной группы приводит к восстановлению нормального физиологического состояния пищевода, эффективно воздействуя на лежащие в основе патологии причины: повышают тонус нижнего пищеводного сфинктера, усиливают перистальтику пищевода и улучшают пищеводный клиренс. С этой целью назначается мотилиум (или другие представители этой группы) по 0,1 г 3 раза в день, за 20 минут до еды, в среднем курсом 3-4 недели $[16,32,35]$.

\section{- Хирургическое лечение}

Целью операций, направленных на устранение рефлюкса, является восстановление нормальной функции кардии.

Показания к оперативному лечению:

- безуспешность консервативного лечения;

- осложнения ГЭРБ (стриктуры, повторные кровотечения);

- частые аспирационные пневмонии;

- пищевод Барретта при гистологически подтвержденной дисплазии высокой степени из-за опасности малигнизации;

- необходимость долгосрочной антирефлюксной терапии у молодых пациентов с ГЭРБ $[6,7,13,38]$.

Таким образом, проблемы своевременной диагностики, лечения и профилактики ГЭРБ остаются на повестке дня современной медицинской науки и их успешное разрешение возможно лишь при самом тесном взаимодействии научных исследований с практическим здравоохранением и пропагандой здорового образа жизни.
1. Бабак М.О. Факторы адиноцитарного происхождения в развитии ГЭРБ и осложнений при ожирении, персонифицированная тактика лечения в зависимости от фармакогенома / М.О. Бабак // Сучасна гастроентерологія. 2008. — № 6(44). - С. 78-84.
2. Бабак О.Я. Гастроэзофагеальная рефлюксная болезнь: от понимания механизмов развития заболевания к уменьшению клинических симптомов / О.Я. Бабак, Е.В. Колесникова // Сучасна гастроентерологія. — 2012. — № 3(65). C. $32-38$. 
3. Бордин Д.С. «Кислотный карман» как патогенетическая основа и терапевтическая мишень при гастроэзофагеальной рефлюксной болезни / Д.С. Бордин // Терапевтический архив. -2014 . - № 2. - С. 76-80.

4. Гриневич В.Б. Гастроэзофагеальная рефлюксная болезнь и ее внепищеводные проявления - современные представления о диагностике и лечении./ В.Б. Гриневич, О.А. Саблин. - СПб.: Бреста, 2004. - 172 с.

5. Джулай Г.С. Клинико-патогенитические варианты гастроезофагеальной рефлюксной болезни: факторы риска и предикторы развития./ Г.С. Джулай, Е.В. Секарева, B.М. Курицин // Терапевтический архив. - 2013. № $2 .-$ С. $8-13$.

6. Ивашкин В.Т. Национальное руководство. Гастроэнтерология. Краткое издание // ГЭОТАР- Медиа. — 2012. $480 \mathrm{c}$.

7. Маев И.В. Гастроэзофагеальная рефлюксная болезнь / И.В. Маев, Г.Л. Юренев, Г.А. Бусарова // Российский журнал гастроэнтерологии, гапатологии и капрологии. 2012. - № 5. - С. 13-23.

8. Маев И.В. Особенности течения гастроэзофагеальной рефлюксной болезни у больных сахарным диабетом 2 типа / И.В. Маев, Г.Л. Юренев, Д.А. Кахраманова// Клиническая медицина. - 2012. - № 9. - С. 53-57.

9. Мамаев Н.В. Функциональная активность альвеолярных макрофагов у больных бронхиальной астмой и гастроэзофагеальной рефлюксной болезнью / Н.В. Мамаев, С.В. Лямина, С.В. Калиш, Е.В. Малышева // Клиническая медицина. - 2013. - № 6. - С. 41-47.

10. Минушкин О.Н. Изучение эпидемиологических особенностей эрозивной и неэрозивной форм гастроэзофагеальной рефлюксной болезни (ГЭРБ) / О.Н.Минушкин, Л.В. Масловский, О.Ю. Теплухина и др. // Росс. журнал гастроэнтерологии, гепатологии и капрологии. - 2005. № 5. - C. $11-15$.

11. Морозов С.В. Лечение больных неэрозивной формой гастроэзофагеальной рефлюкной болезнью / С.В. Морозов, Ю.А. Кучерявый // Лечащий врач. - 2013. - № 7. C. $32-38$.

12. Немцов В.И. Использование ингибиторов пртонной помпы (ИПП) с быстрым началом антисекреторного действия для лечения рефрактерной формы гастроэзофагеальной рефлюксной болезни (ГЭРБ) / В.И. Немцов. - С.П.:Гастроэнтерология, 2012. - №2-3. - 65с.

13. Опарин А.А. Лекции по гастроэнтнрологии./ А.А. Опарин, А.Г. Опарин, Н.В. Лаврова, Ю.И. Двояшкина. - Харьков : Факт, 2013. - 175c.

14. Опарин А.А. Мелатонин и заболевания желудочнокишечного тракта./ А.А.Опарин, О.Е. Шаповалова, Ю.И. Двояшкина, Н.В. Лаврова // Міжнародний медичний журнал. - 2010. - № 4(65). - С. 68-72.

15. Опарин А.А., А.Г.Опарин, И.П. Кореновский, Н.В. Лаврова Алгоритмы и критерии УЗИ- диагностики в клинике внутренних болезней / Под ред. проф. А.А. Опарина. Харьков: Факт. - 2012. - 80 с.

16. Опарин А.Г. Роль мелатонина в формировании секреторнодвигательных расстройств при гастроэзофагеальной рефлюксной болезни с учетом психосамотического статуса у студентов / А.Г. Опарин, А.А. Опарин, О.Е. Шаповалова// Світ медицини та біології. - 2010. - № 1. - С. 110-113.

17. Опарин А.Г., Опарин А.А., Лаврова Н.В., Кореновский И.П. Клиническая фармакология в гастроентерології // Под ред. А.А. Опарина. - Харьков: Факт. - 2013. - 80 с.

18. Осадчук М.А. Клинико-эндоскопические и морфофункциональные показатели в оценке развития гастроэзофа- геальной рефлюксной болезни в различных возрастных группах / М.А. Осадчук, А.М. Золотовицкая, И.В. Киреев и др. // Рос. журнал гастроэнтерологии, гепатологии и колонопроктологии. — 2012. — №5. - С.30-36.

19. Рязанцева Д.Е. Оценка гендерных особенностей качества жизни больных гастроэзофагеальной рефлюксной болезнью / Д.Е. Рязанцева, Е.Ю. Еремина // Гастроэнтерология. - Санк-Петербург, 2012. - №2-3. - С.76.

20. Скрипник І.М. Оверлап - синдром неерозивної рефлексної хвороби та функціональної диспепсії: клінікоепідеміологічний аналіз та лікування./ I.М. Скрипник, Г.В. Осьодлова, І.М. Шевага // Сучасна гастроентерологія. — 2012. — № 2(64). — С. 42-48.

21. Степанов Ю.М. Шляхи оптимізації лікування гастроєзофагеальної рефлексної хвороби./ Ю.М. Степанов, І.Я. Будзяк, С.В. Косинська // Сучасна гастроентерологія. - 2012. — № 2(64). - С. 109-113.

22. Сторонова О.А. Нарушения пищеводного клиренса при гастроэзофагеальной рефлюксной болезни и возможности их коррекции./ О.А. Сторонова, А.С. Трухманов, Н.Л. Джахая, В.Т.Ивашкин // Росс. журнал гастроэнтерологии, гепатологии и колонопроктологии. - 2012. - № 2. C.14-21.

23. Ткач С.М. Клиническая польза и потенциальный риск применения ингибиторов протонной помпы / С.М. Ткач // Український терапевтичний журнал. - 2012. — № 3-4. C. $123-130$.

24. Ткач С.М. Современные показания к применению повышенных доз ингибиторов протонной помпы / С.М. Ткач // Сучасна гастроентерологія. — 2011. — № 5. C. $45-52$.

25. Трухманов А.С. Диагностика и лечение гастроэзофагеальной рефлюксной болезни / А.С.Трухманов // Терапевтический архив. - 2011. - № 8. - С. 44-48.

26. Успенский Ю.П. Патогенетические основы дифференцирования тактики лечения гастроэзофагеальной рефлюксной болезни./ Ю.П. Успенский, Е.И. Ткаченко // Сучасна гастроентерологія. - 2010. — № 1(51). - С. 92-101.

27. Фадеенко Г.Д. Гастроэзофагеальная рефлюксная болезнь и Helicobacter pylori./ Г.Д. Фадеенко, А.Е. Гриднев // Сучасна гастроентерологія. - 2014. — № 1(75). — С. 93-95.

28. Фадеенко Г.Д. Лечение гастроэзофагеальной рефлюксной болезни у пациентов с ожирением: роль и место современного прокинетика итоприда гидрохлоридаю / Г.Д. Фадеенко, Т.Л. Можина // Сучасна гастроентерологія. - 2011. № 1 (57). - С. $71-77$.

29. Харченко Н.В. Обзор материалов 21-й ежегодной Европейской гастроэнтерологической недели / Н.В. Харченко, И.М. Скрипник // Журнал «Здоров’я України». - 2014. №01-02(326-327). - С. 34-35.

30. Харченко Н.В. Применение препаратов альгиновой кислоты в терапии больных с гастроэзофагеальной рефлюксной болезнью / Н.В. Харченко, Д.Т. Джанелидзе, И.С. Марухно, О.М. Герасименко // Сучасна гастроентерологія. - 2014. — № 2(76). - С. 47-51.

31. Цуканов В.В. Клинические аспекты гастроэзофагеальной рефлюксной болезни у лиц пожилого возраста: результаты 5-летнего исследования / В.В. Цуканов, Е.В. Онучина, А.В. Васютин и др. // Терапевтический архив. - 2014. № 2. - C. $23-26$.

32. Чернявский В.В. Коррекция секреторной и моторноэвакуаторной функции желудка как краеугольный камень предупреждающий рецидив гастроэзофагеальной рефлюксной болезни / В.В. Чернявский // Сучасна гастроентерологія. - 2012. — № 1(63). - С. 120-124. 
33. Шварц Ю.Г. Анемия и гастроэзофагеальная рефлюксная болезнь у больных ишемической болезнью сердца./ Ю.Г. Шварц, С.А. Суворова, И.В.Козлова, Е.В.Пархонюк // Клиническая медицина. - 2012. - № 9. - С.47-49.

34. Шептулин А.А. Внепищеводные проявления гастроэзофагеальной рефлюксной болезни / А.А. Шептулин, В.А. Киприанис // РЖГГК. - 2005. — № 5. - С.1015.

35. Щербинина М.Б. Новые стратегии в лечении гастроэзофагеальной рефлюксной болезни / М.Б. Щербинина, Е.В. Закревская, Т.А. Скороход // Сучасна гастроентерологія. - 2010. — № 4(54). - С. 83-89.

36. Янова О. Современное понимание патофизиологических аспектов ГЭРБ и подходы к ее фармакотерапии./ О. Янова// Фармакология. - 2013. - № 3. - С. 35-40.

37. Adachi K. Radially asymmetric gastroesophageal acid reflux in the distal esophagus: examinations with novel $\mathrm{pH}$ sensor catheter equipped with $8 \mathrm{pH}$ sensors / K. Adachi, S. Ohara, K. Furuta // Journal of Gastroenterology. - 2012. - Vol. 47. — № 11. - R. 12211227.
38. Dzhulay S.G. Clinical and pathogenetic varyantb gastroesophageal reflux illness: factors and predictors of risk of development / S.G. Dzhulay, E.V. Sekareva V.M. Kurytsыn // therapeutic Archives in 2013. - № 2. - S. 8 -12.

39. Heine K.J. Crural diaphragm and lower esophageal sphincter as ant reflux barriers / KJ Heine, R.K. Mittal // Viewpoints in Digestive Diseases. - 2010. - $23 \mathrm{p}$.

40. Karataev A.E six nozhey in the back proton inhibitors pomры / A.E. Karataev // Scientific-practical revmatolohyya. - 2013. № 3 (51). - P. 332-340.

41. Katz P.O. Guidelines for the Diagnosis and Management of Gastroesophageal Reflux Disease / PO Katz, L.B.Gerson, M.F. Vela // The American Journal of Gastroenterology. 2013. - Vol. 108. - P. 308-328

42. Mittal R. Sphincter mechanisms at the esophago-gastric junction / R. Mittal // Springer New York. — 2013. - P. 319341.

43. Mittal R. Transient lower esophageal sphincter relaxation / R.Mittal,H.Holloway, R. Penagini [etal.] // Gastroenterology.2011. - P.109 - 117.

\title{
Гастроезофагеальна рефлюксна хвороба. Проблематика. Діагностика. Лікування
}

\author{
Проф. О.А. Опарін, доц. Н.В. Лаврова
}

Харківська медична академія післядипломної освіти

У лекції розглянуті особливості сучасного стану проблематики ГЕРХ: ї̈ формування, поширеності й механізмів виникнення, зроблений аналіз особливостей клінічної картини й можливостей того або іншого диагностичного методу при постановці діагнозу даного захворювання. Наведені пропоновані сьогодні схеми патогенетической терапії й методів профілактики захворювання.

Ключові слова: гастроезофагеальна рефлюксна хвороба, кислотність, інгібітори протонної помпи.

\section{Gastroesophageal reflux disease. Range of problems. Diagnostics. Treatment}

\section{Prof. A.A. Oparin, PHD N.V. Lavrova}

Kharkiv Medical Academy of Postgraduate Education

The lecture describes the features of the current state of GERD issues: its formation, prevalence and mechanisms of genesis, the analysis of clinical features and capabilities of using different methods in the diagnostics of this disease. The recommended scheme of pathogenetic therapy and methods of prevention of the disease are also mentioned in the lecture.

Key Words: gastroesophageal reflux disease, acidity, proton pump inhibitors.

Контактна інформація: Опарін Олексій Анатолійович зав. кафедрою терапії, ревматології та клінічної фармакології ХМАПО, доктор медичних наук, професор. м. Харків, вул. Дарвіна, 10, р. т. (057) 711-75-00, (057) 706-46-17, e-mail: teraprevm@med.edu.ua.

Стаття надійшла до редакції 25.09.2014 p 